\title{
IMPACTOS AMBIENTAIS CAUSADOS PELO TURISMO NA SERRA DA PIEDADE/MG: PROPOSTAS PARA EDUCAÇÃO AMBIENTAL
}

Fernanda Mara Coelho Pizani - fm.coelho@yahoo.com.br Universidade Federal de Minas Gerais

Janaína Letícia Rodolfo - janainarodolfo0@ gmail.com Pontifícia Universidade Católica de Minas Gerais

Daniele Gomes Pereira - danielegeografia@gmail.com.br Pontifícia Universidade Católica de Minas Gerais

Heleno Souza Lima - heleno_geo.lima@yahoo.com.br Pontifícia Universidade Católica de Minas Gerais 


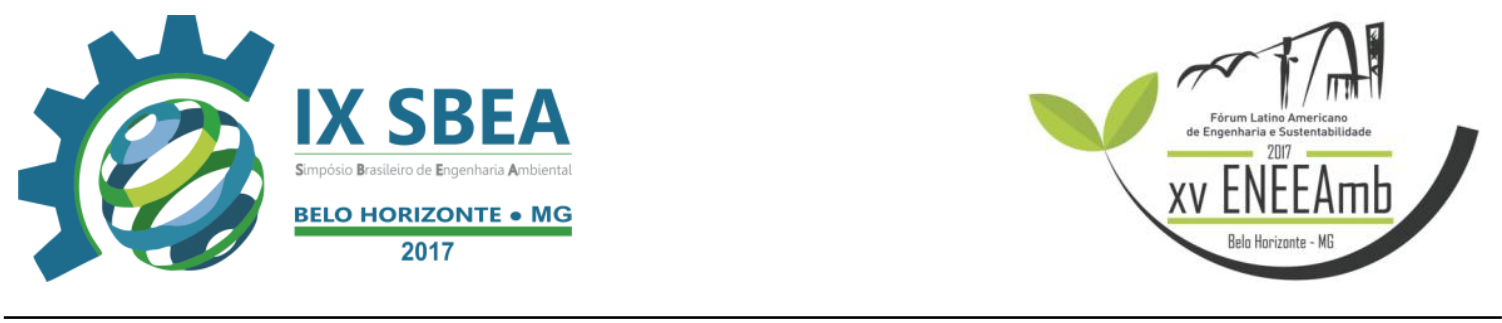

\section{RESUMO}

O presente trabalho visa apresentar uma análise em função da atuação do turismo presente na Serra da Piedade a fim de compreender sua dinâmica e seus impactos no meio ambiente por meio da análise de dados integrados utilizando o método adaptado de Manejo do Impacto de Visitação VIM (Visitor Impact Management) simplificado para identificar os impactos ambientais. Como resultado, foram indicadas as fragilidades da área e apresentadas estratégias de conservação focada em educação ambiental como subsídio aos órgãos de atuação local.

Palavras-chave: Impacto ambiental, Educação ambiental, Turismo.

\section{INTRODUÇÃO/OBJETIVO}

Localizado acerca de $50 \mathrm{~km}$ da capital Belo Horizonte, o maciço da Serra da Piedade encontra-se na divisa dos municípios de Sabará e Caeté/MG, inserido no complexo da Serra do Curral, borda norte do Quadrilátero Ferrífero (Figura 1).

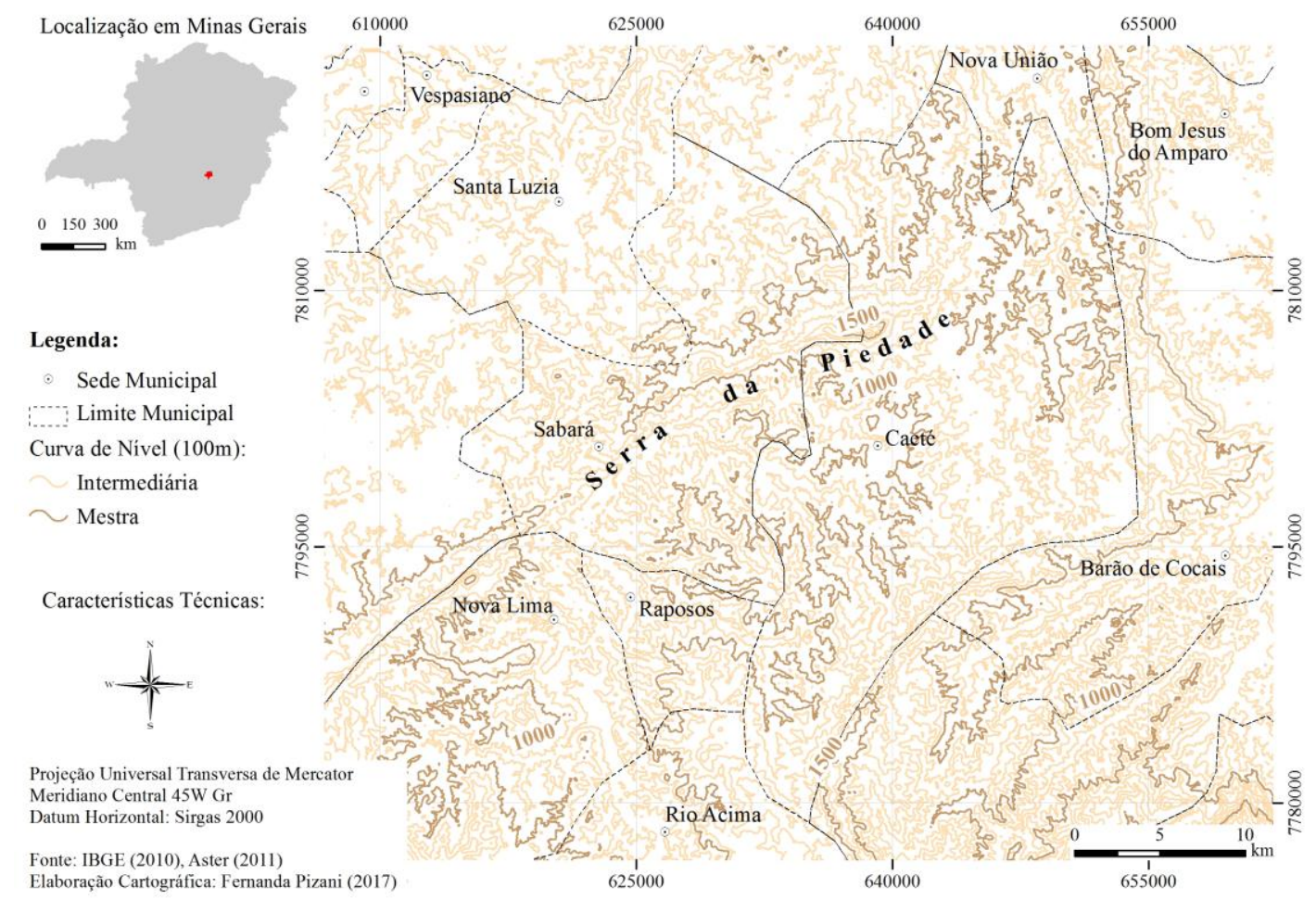

Figura 1 - Mapa de Localização da Serra da Piedade 


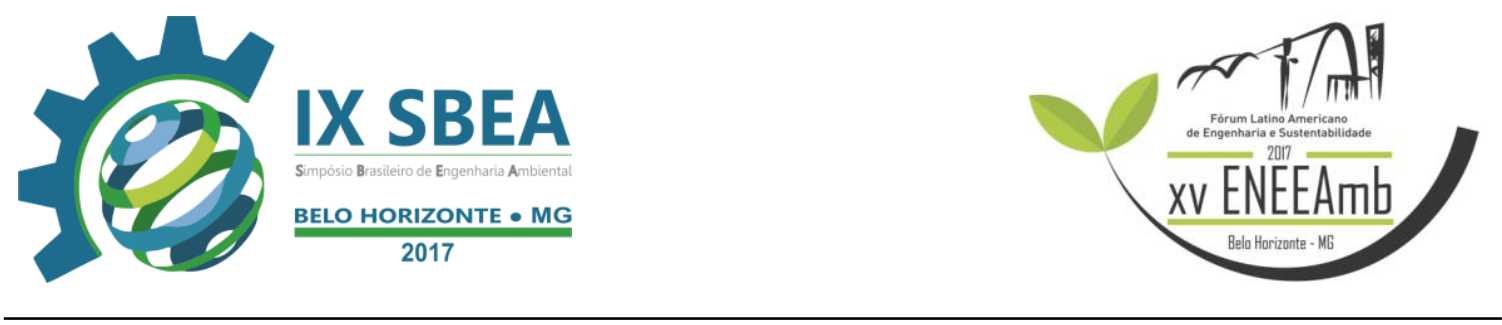

Devido a seus recursos minerais a região do Quadrilátero Ferrífero tornou-se, há muito tempo, alvo de estudos e mapeamentos geológicos, evidenciando sua importância no que tange o desenvolvimento econômico regional e nacional. Neste contexto, a Serra da Piedade se destaca desde o início da ocupação da região, que se deu em meados do século XVII (RUCHKYS et al., 2009).

É importante frisar não só a importância econômica por meio da extração de seus recursos, mas também a importância biológica presente na área de estudo. A Serra abriga uma grande diversidade de espécies animais e vegetais sendo considerada um remanescente de Mata Tropical e um refúgio da vida urbana. Segundo Ruchkys et al. (2009), é possível encontrar no local espécies de flora ameaçadas de extinção.

Entretanto, a Serra se destaca e é reconhecida por um fundamental elemento: seu valor religioso e turístico. Atualmente, além das visitas eventuais durante o ano de pessoas vindas de todos os lugares de Minas Gerais, a Serra também recebe a visita de fiéis durante as datas celebradas pela Igreja Católica, de peregrinos e pagadores de promessa.

Somado ao volume de romeiros, o local atrai uma grande parcela de turistas em busca de adrenalina que fazem trilha de moto e bicicleta, além dos que praticam caminhadas ecológicas, escaladas, tirolesa, entre outras atividades em meio à natureza.

A Serra ainda conta com visitas eventuais durante o ano de pessoas vindas de todos os lugares de Minas Gerais. O vínculo da paisagem natural confortante com o local de paz, retiro e oração desperta no turista a vontade de descobrir a Serra da Piedade, seja pela sua beleza paisagística ou pela religiosidade empregada ali.

Sendo uma atividade humana promissora, o turismo não está isento de provocar impactos sejam eles físicos, bióticos ou socioculturais. De um modo geral, as paisagens sofrem alterações devido a instalação ou a ausência de infraestrutura para atender o público. No caso da Serra da Piedade, a inserção do município de Caeté no Circuito Estrada Real de Turismo, tem como objetivo promover a atividade turística local, mas não foram identificadas ações notórias para a avaliação dos impactos ambientais ou propostas de sustentabilidade.

Desta forma, este trabalho pretende apresentar uma análise em função da atuação do turismo presente na Serra da Piedade a fim de compreender sua dinâmica e 


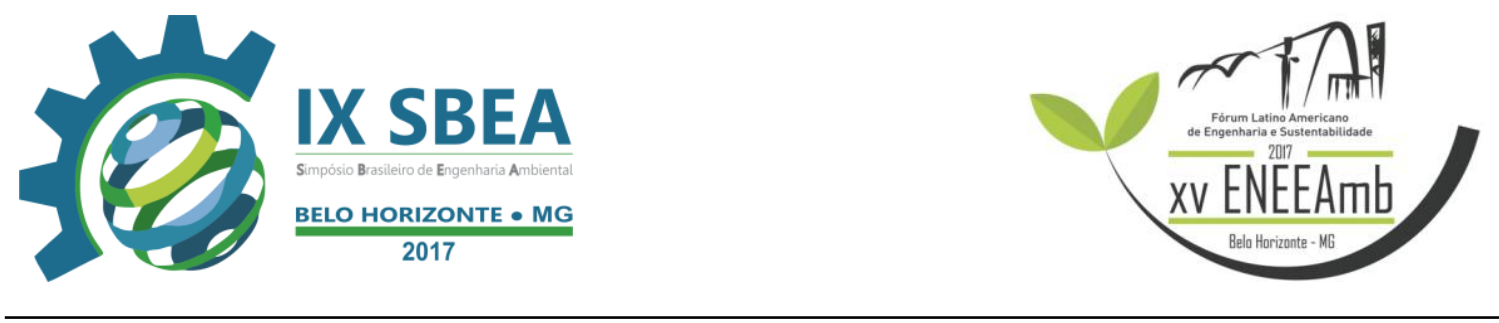

seus impactos no meio ambiente tendo como base três principais trilhas previamente identificadas no local. Para tanto, objetiva-se, por meio de uma integração de dados, realizar uma análise de maneira local utilizando o método adaptado de Graefe et al. (1990) para o Manejo do Impacto de Visitação denominado VIM (Visitor Impact Management), de forma simplificada, a fim de identificar os impactos ambientais propondo estratégias para a conservação focada em educação ambiental.

\section{METODOLOGIA}

O desenvolvimento desta pesquisa se deu, inicialmente, por um sólido levantamento bibliográfico que embasou conceitos aqui trabalhados, tais como importantes considerações acerca da educação ambiental, dos impactos ambientais e do turismo, primordialmente.

Efetivada a revisão bibliográfica, foram realizadas visitas a campo que permitiram o mapeamento e a caracterização de três principais trilhas de acesso ao Alto da Serra, onde se encontram o Santuário Nossa Senhora da Piedade, a Gruta do Eremita e o Observatório Astronômico da Universidade Federal de Minas Gerais (Figura 2).

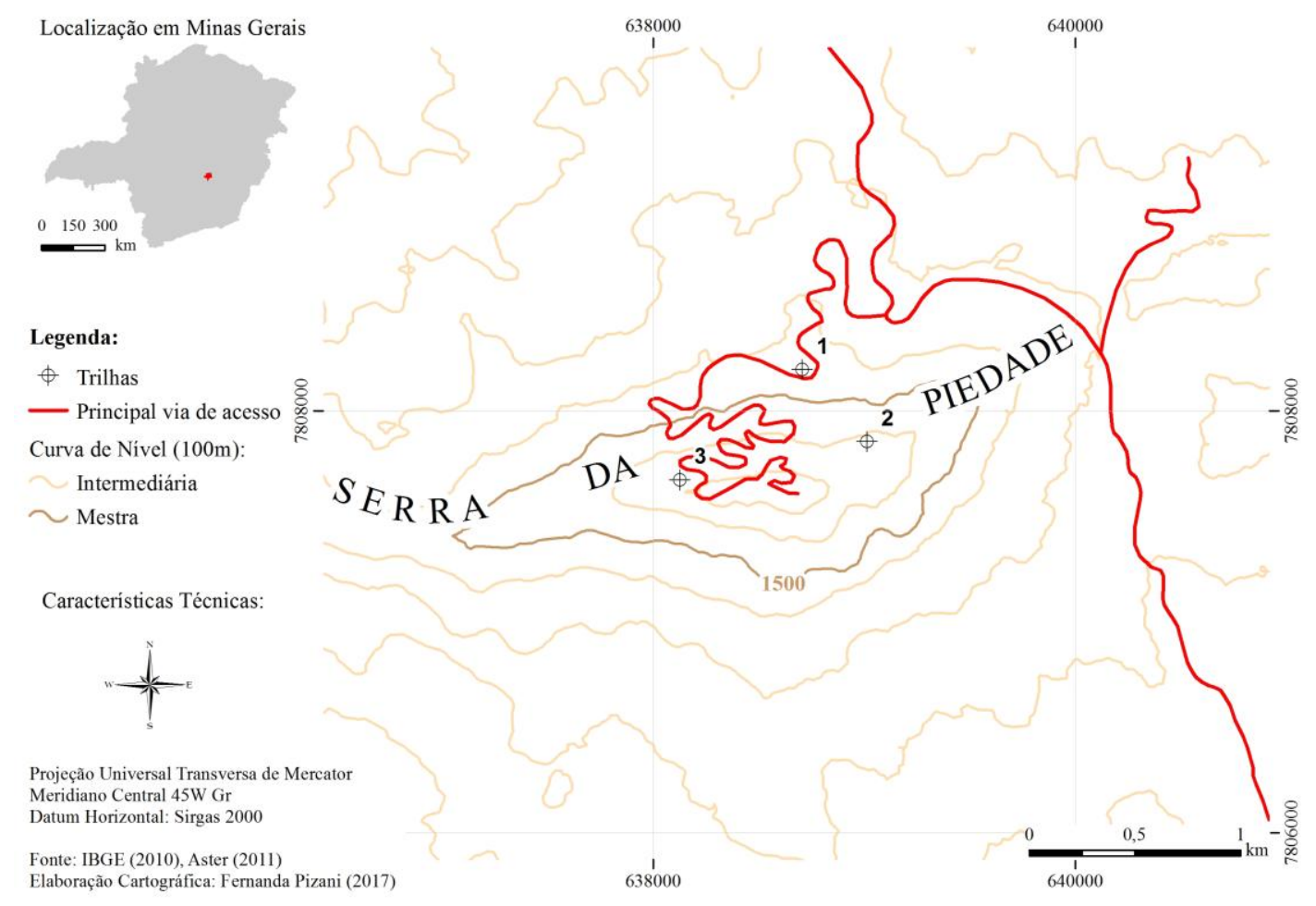

Figura 2 - Localização das trilhas mapeadas 


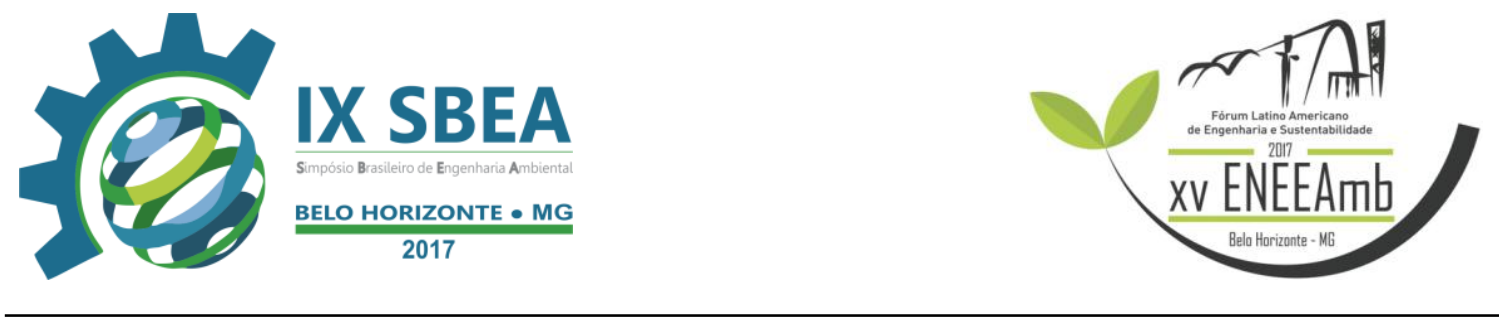

Em posse das informações obtidas, foi possível selecionar e identificar indicadores mensuráveis para as possíveis causas dos impactos ambientais da área de estudo. Desta forma, elaborou-se uma matriz de avaliação a fim de indicar de forma simplificada os impactos presentes tendo como base as três trilhas estudadas. A aplicação da matriz de avaliação foi adaptada do método VIM (Visitor Impact Management) proposto por Graefe et al. (1990), que tem por finalidade a sugestão para a adoção de estratégias adequadas para o manejo e monitoramento dos impactos identificados na área de estudo. A Figura 2 exprime um fluxograma que indica a metodologia aplicada a este estudo.
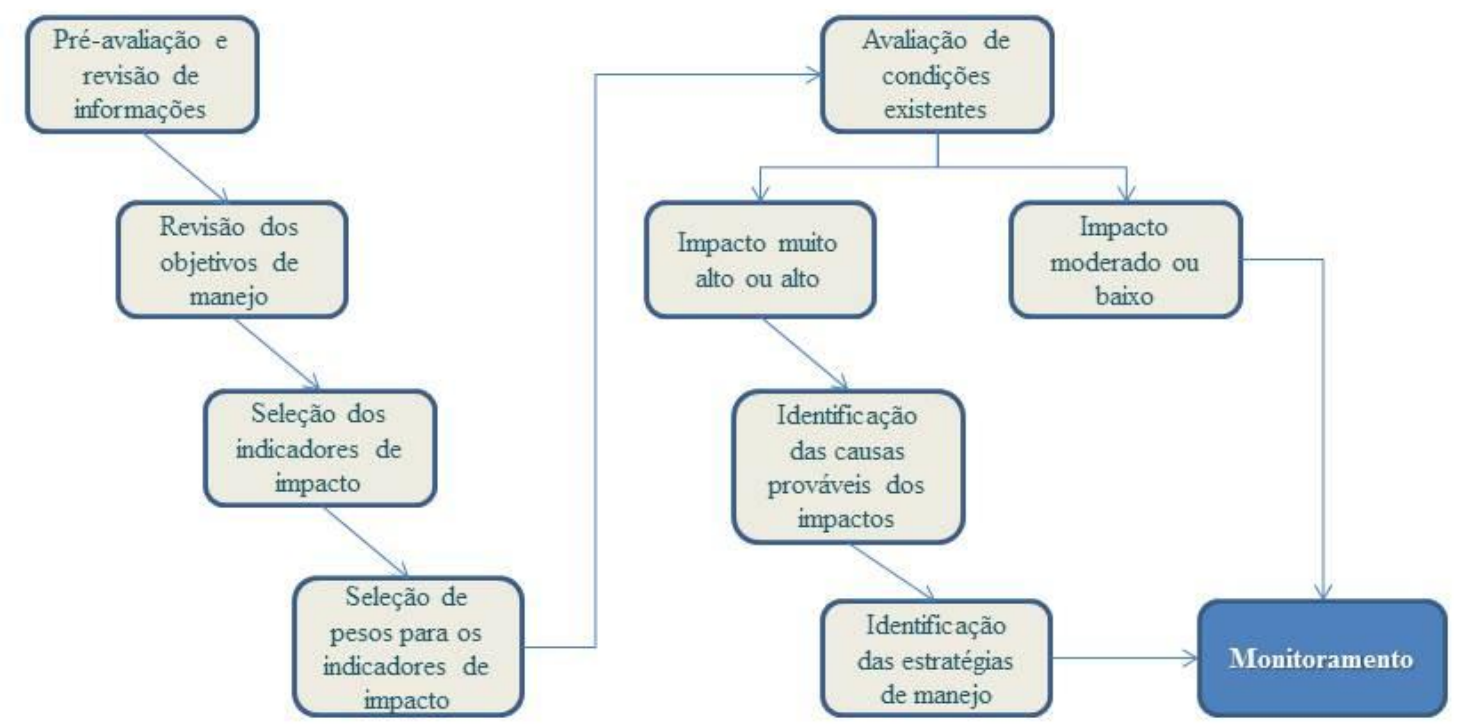

Figura 2 - Fluxograma das etapas metodológicas

Fonte: Adaptado de Graefe et al. (1990); Sardinha et al. (2007)

A partir de então, foram identificadas estratégias de manejo e realizada a proposta de educação ambiental na Serra da Piedade. Esta pôde ser definida de forma adequada e mais direcionada, já que os principais focos de impacto foram préestabelecidos.

\section{RESULTADOS E DISCUSSÃO}




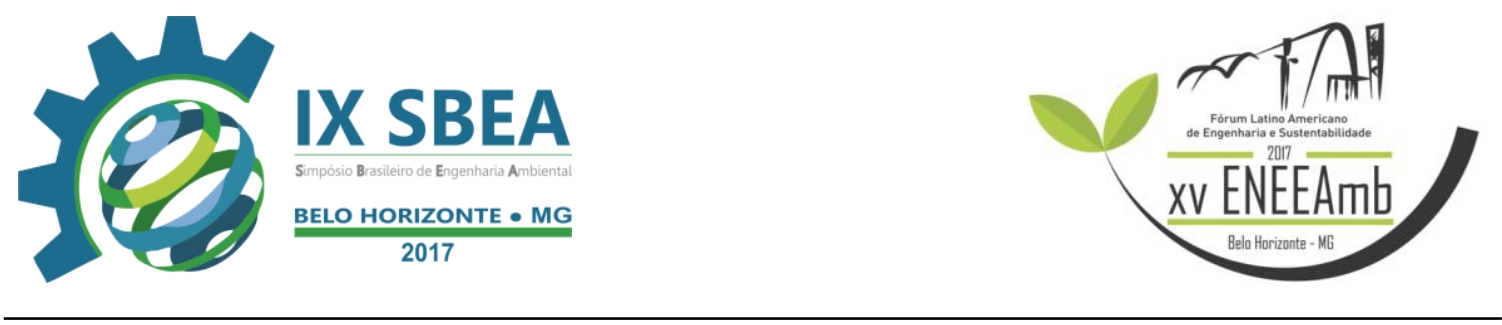

A primeira trilha mapeada se caracteriza pela vegetação de pequeno porte e presença de descampados. Esta trilha sofre com a coleta de espécies de flora feitas pelos visitantes e com as queimadas acidentais ou intencionais.

À medida que se sobe a Serra, a vegetação diminui de porte tornando-se mais aberta, predominando uma vegetação de cerrado e de campos de altitude. A segunda trilha é caracterizada por espécies com finos tronco, pequenos galhos e folhas, fragmentos de rochas, solo com presença de sulcos nas laterais, raízes expostas e presença do mineral hematita em grande quantidade. Nesta trilha pode-se verificar a continuidade de formação de novas e pequenas trilhas feitas por visitantes em suas caminhadas e por motociclistas. Nesta porção é possível encontrar a maior concentração de lixo e um processo erosivo avançado.

Mais próximo ao topo, coberto pela canga, encontra-se a terceira trilha que é caracterizada por uma cobertura de campo rupestre que se desenvolve tipicamente sobre as formações do Quadrilátero Ferrífero. A vegetação cresce sobre um solo composto de fragmentos muito duros denominados canga nodular ou sobre rochas com fendas onde as raízes podem penetrar. Nesta porção, a degradação é contínua devido a proximidade e acessibilidade proporcionada pela construção do Santuário, para o qual os romeiros se dirigem durante todo o ano e principalmente na Festa da Padroeira.

Durante o período do jubileu é montada uma maior infraestrutura para receber os visitantes, mas isto não impede que o local sofra com os danos. Há um grave problema no que tange a coleta de lixo, uma vez que esta somente é contratada na época do jubileu, ficando o resto dos meses a cargo dos funcionários do restaurante que fazem a coleta somente das imediações do Santuário. A estrada que dá acesso a Serra possui lixeiras somente no quilômetro 3 (onde se encontra o estacionamento dos ônibus, sanitários e a primeira lanchonete) e no quilômetro 5 (topo da serra), o que agrava ainda mais a situação. Durante o período festivo, apesar de haver estacionamento para os ônibus dos romeiros, alguns veículos alternativos estacionam às margens da estrada de acesso para que os peregrinos possam fazer o trajeto a pé, o que pode ocasionar a degradação da vegetação.

Dentre os recursos levantados, a Serra abriga nascentes distribuídas em toda sua extensão do Rio Xopotó, Córrego de Santa Maria e Ribeirão da Piedade que abastecem 
as cidades de São Geraldo, Visconde do Rio Branco e Guidoval (SLAIBI, 2005) sendo também responsável, juntamente a Bacia do Ribeirão Bonito, por cerca de $75 \%$ da água consumida em Caeté (SALGADO \& MAGALHÃES JUNIOR, 2006). Nas instalações locais (igreja e restaurante) questionou-se acerca do destino de toda água usada nos sanitários e limpeza, entretanto, não foram obtidas respostas. Existe um grande risco de que esta água esteja sendo despejada próxima a alguma das nascentes, o que pode gerar sua contaminação.

Quanto à fauna, todo o conjunto deste ecossistema propicia a existência de espécies como capivara, coelho, jaguatirica, paca, porco vermelho, entre outras. Estas espécies encontram ali condições favoráveis à alimentação e abrigo. Verificou-se que muitas delas acabam abandonando seu habitat, devido a sua intolerância à presença dos turistas. Isto faz com que muitas destas espécies se retirem, indo para as margens da estrada aumentando o risco de morte por veículos, o que contribui para um aumento da extinção e, consequentemente, para um desequilíbrio do ecossistema local.

A degradação dada pelas inscrições nas rochas, placas, paredes e monumentos se encontram por todo o topo da Serra e, principalmente, próximo à terceira trilha, onde se faz o caminho para a Gruta do Eremita. A gruta, que deveria ser resguardada em respeito à memória dos moradores de Caeté e dos frequentadores religiosos do lugar que valorizam seu significado como local de retiro, encontra-se deteriorada e padece devido ao odor e a má conservação.

Levantados os impactos ambientais da área de estudo, foi possível desenvolver a matriz de avaliação adaptada de Graefe et al. (2000) pelo método VIM (Tabela 1):

Tabela 1 - Matriz de avaliação por monitoramento de indicadores biofísicos.

\begin{tabular}{|l|c|c|c|c|c|}
\hline \multirow{2}{*}{ INDICADOR / Verificador } & \multicolumn{5}{|c|}{ Trilha } \\
\cline { 2 - 6 } & $\mathbf{1}$ & $\mathbf{2}$ & $\mathbf{3}$ & $\sum$ \\
\hline VEGETAÇÃO & 1 & 0 & 0 & $\mathbf{1}$ \\
\hline Número de indícios de fogo & 1 & 2 & 0 & $\mathbf{3}$ \\
\hline LEITO TRILHA & 0 & 0 & 0 & $\mathbf{0}$ \\
\hline Erosão (0/1/2/3) & 2 & 3 & 1 & $\mathbf{6}$ \\
\hline Problemas de drenagem (s/n) &
\end{tabular}




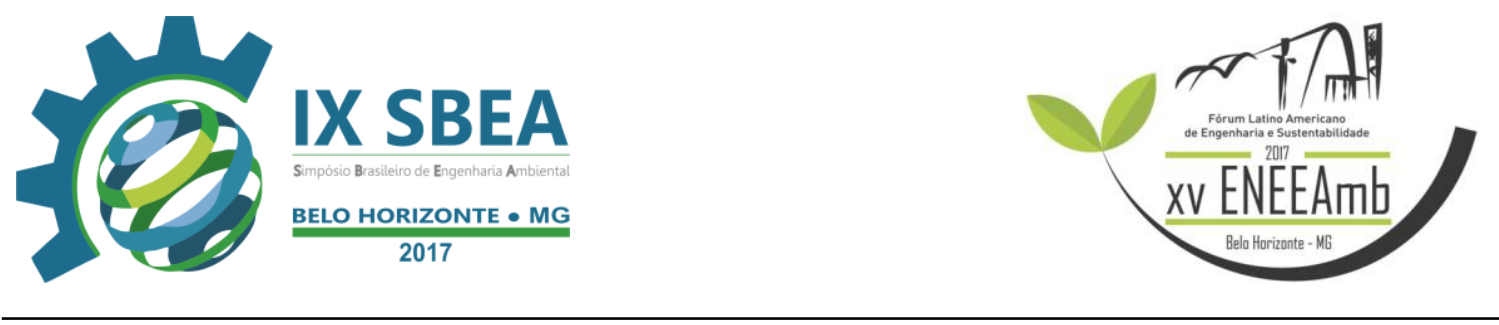

\begin{tabular}{|l|c|c|c|c|c|}
\hline Profundidade (m) & - & - & - & - \\
\hline Problemas de risco (s/n) & 1 & 1 & 1 & $\mathbf{3}$ \\
\hline DANOS & 0 & 1 & 1 & $\mathbf{2}$ \\
\hline Vandalismo em estruturas (s/n) & 1 & 1 & 1 & $\mathbf{3}$ \\
\hline Inscrições em rochas (s/n) & 0 & 0 & 3 & $\mathbf{3}$ \\
\hline Número de árvores com danos / inscrições & 1 & 2 & 1 & $\mathbf{4}$ \\
\hline SANEAMENTO & 1 & 1 & 0 & $\mathbf{2}$ \\
\hline Lixo na trilha (1-p/2-m) & 1 & 1 & 1 & $\mathbf{3}$ \\
\hline Lixo fora dos latões (1-p/2-m/3-tr) & 0 & 0 & 1 & $\mathbf{1}$ \\
\hline Problemas de saneamento (1-dj/2-ur/3-fs-eg/4-et) & $\mathbf{7}$ & $\mathbf{9}$ & $\mathbf{9}$ & - \\
\hline SOM & 7 &
\end{tabular}

Em posse dos impactos quantificados, tornou-se possível elaborar estratégias de manejo para serem implementadas a curto e médio prazos.

\section{CONCLUSÕES/RECOMENDAÇÕES}

Verificou-se que os problemas de erosão, inscrições em rochas e árvores, lixos nas trilhas e saneamento são os mais graves e os que mais necessitam de uma atenção especial, visto que os problemas estão tomando proporções espaciais amplas. A conscientização tem papel importante para conservar o patrimônio que está pedindo ajuda, uma vez que se percebe que a maioria dos problemas descritos aqui e verificados no local são de origem humana e fácil reversão se houver uma conscientização adequada.

Apesar de sua beleza paisagística e de sua atração voltada para o público religioso, a Serra corre grande perigo em relação à degradação, que cresce rapidamente, uma vez que há uma tentativa constante do governo local em reaquecer a economia, forçando a atividade turística.

Houve uma melhora local significativa nos últimos seis anos no que tange à infraestrutura do patrimônio no caminho de acesso ao topo da Serra da Piedade, mas ainda é possível aprimorar especialmente na instalação de lixeiras no acesso principal e 


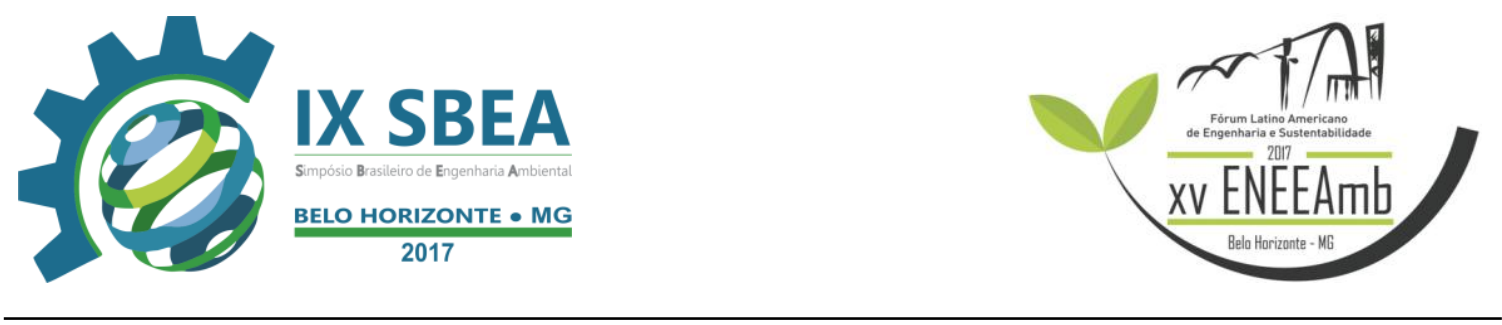

fiscalização nas trilhas e atrativos turísticos. Zelar pelo patrimônio é garantir que a Serra não se mantenha exposta aos danos ambientais. Desta forma, outros meios de educação ambiental devem ser investigados para solucionar o problema local.

No caso específico da Serra da Piedade, é possível observar projetos que já existem nas escolas sobre educação ambiental, entretanto com enfoque somente na atividade mineradora. Pode-se citar movimentos como o "SOS Serra da Piedade", com grande participação de alunos e professores das escolas de Caeté. Estes projetos, no entanto, não contemplam as atividades causadas pelo turismo.

Entende-se que as escolas possam ser trabalhadas como um importante instrumento na conscientização da sociedade em geral. Desta forma, recomenda-se que a educação ambiental seja lidada, primeiramente, em seu contexto formal, ou seja, praticada nas escolas sob a orientação do corpo docente (BRASIL, 1999). A sugestão inicial é que se preze uma alfabetização ecológica baseada nas propostas de Capra (1996), onde noções de ecologia, meio ambiente e cidadania sejam trabalhadas. Acompanhando o desenvolvimento teórico, é possível unir estes conhecimentos adquiridos a práticas de campo para problematização das ocorrências locais.

Em um segundo momento, recomenda-se que se estabeleça a prática da educação não-formal, ou seja, que haja o envolvimento de ações e práticas educativas voltadas a sensibilização da sociedade sobre questões ambientais e a sua organização e participação na defesa do meio ambiente (BRASIL, 1999). Esta prática pode ser desenvolvida, aliada ao ambiente educacional por meio de ações voluntárias ou realizadas em parceria com o governo, de encontro com os turistas para explanar brevemente acerca da riqueza histórica, paisagística e cultural da Serra. É importante destacar quão grave é a coleta de espécies, a importância de se armazenar o lixo produzido e os riscos provocados pelo uso do cigarro nas imediações das matas e trilhas.

Por meio desta pedagogia, é possível haver uma compreensão acerca da educação ambiental de forma sistêmica, levando a uma experiência com o mundo real de modo a contribuir para a construção da cidadania, melhoria na qualidade de vida e conservação patrimonial. 


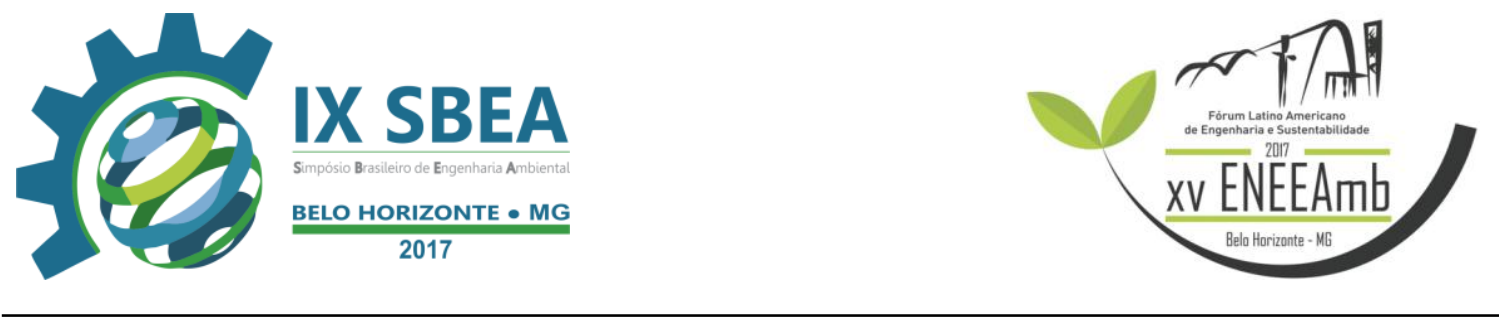

É importante frisar que o método VIM não tem por finalidade a conclusão ou fechamento da pesquisa quando se torna efetiva a implementação recomendada. É necessário um monitoramento contínuo dos impactos levantados a fim de verificar o sucesso das ações propostas. Desta forma, cabe ressaltar que este estudo não conclui, mas sim possibilita um auxílio para a implantação de uma educação ambiental, preferencialmente em curto prazo, uma vez que, como já descrito, a Serra da Piedade ainda sofre com a falta de consciência, tanto individual quanto coletiva. É importante zelar pelo patrimônio para que ele viva sempre e não apenas fique na lembrança de seus frequentadores.

\section{REFERÊNCIAS BIBLIOGRÁFICAS}

BANDUCCI, A.; BARRETTO, M. (Org.) Turismo e identidade local: uma visão antropológica. Campinas: Papirus, 2001. 208p.

BRÜGGER, P. Educação ou adestramento ambiental? Chapecó: Letras Contemporâneas, 1999. 159p.

CAPRA, F. A teia da vida: uma nova compreensão científica dos sistemas vivos. São Paulo: Editora Cultrix, 1996. 249p.

CASTRO, C.M.; PEIXOTO, M.N.; RIO, G.A. Riscos ambientais e geografia: conceituações, abordagens e escalas. Anuário do Instituto de Geociências, Rio de Janeiro, v.28, n.2, p.11-30, 2005.

CUNHA, S.B.; GUERRA, A.T. A questão ambiental: diferentes abordagens. Rio de Janeiro: Bertrand Brasil, 2003. 248p.

FREIXÊDAS-VIEIRA, V.M.; PASSOLD, A.J.; MAGRO, T.C. Impactos do uso público: um guia de campo para utilização do método VIM. In: CONGRESSO DE UNIDADES DE CONSERVAÇÃO, 2., Campo Grande. Anais... Campo Grande: Rede Pró-Unidades de Conservação, 2000. p.296-305.

GRAEFE, A.R.; KUSS, F.R.; VASKE, J.J. Visitor Impact Management: the planning framework. Washington: National Parks and Conservation Association, 1990. 105p.

BRASIL. Lei no 9.795, de 27 de abril de 1999. Dispõe sobre a educação ambiental, institui a Política Nacional de Educação Ambiental e dá outras providências. Diário Oficial [da] República Federativa do Brasil, Brasília, 28 abr. 1999. Disponível em: http://www2.camara.leg.br/legin/fed/lei/1999/lei-9795-27-abril-1999-373224-normapl.html. Acesso em: 25 abr. 2017. 


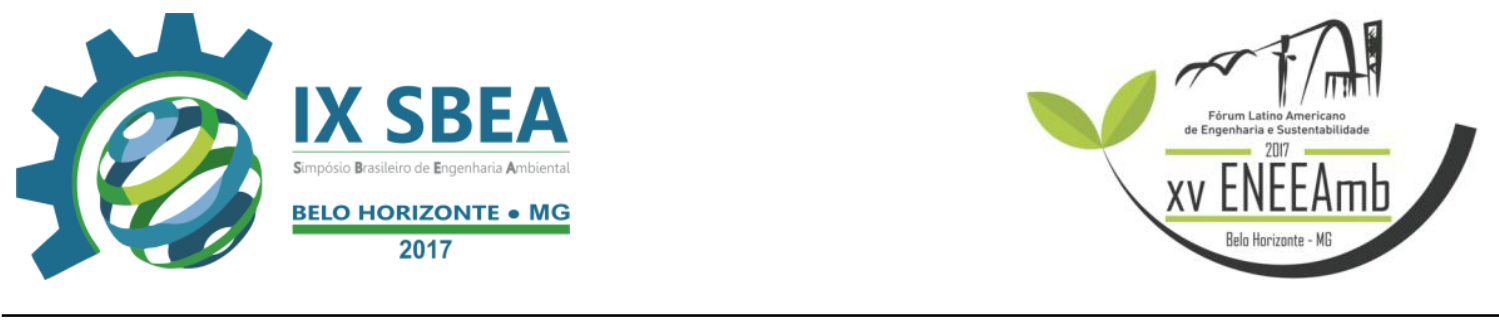

LEMOS, A.I.G. Turismo: impactos socioambientais. São Paulo: Hucitec. 1996. 305p.

REIGOTA, M. O que é educação ambiental. São Paulo: Brasiliense, 1994. 62p.

RODRIGUES, A.A.B. Turismo e espaço: rumo a um conhecimento transdisciplinar. São Paulo: Hucitec, 2001. 158p.

ROSENDAHL, Z. O espaço e religião: uma abordagem geográfica. Rio de Janeiro: UERJ, 1996. 89p.

ROSENDAHL, Z. O sagrado e o espaço. In: CASTRO, I.E.; CORRÊA, R.L.; GOMES, P.C.C. (Orgs.) Explorações geográficas: percursos no fim do século. Rio de Janeiro: Bertrand Brasil, 1997. P.119-154.

ROSENDAHL, Z. O espaço, o sagrado e o profano. In: ROSENDAHL, Z.; CORRÊA, R.L. (Orgs.) Manifestações da cultura no espaço. Rio de Janeiro: UERJ, 1999. P.219247.

RUCHKYS, U.A.; RENGER, F.E.; NOCE, C.M.; MACHADO, M.M.M. Serra da Piedade, Quadrilátero Ferrífero, MG: da lenda do Sabarabuçu ao patrimônio histórico, geológico, paisagístico e religioso. In: WINGE, M.; SCHOBBENHAUS, C.; BERBERT-BORN, M.; QUEIROZ, E.T.; CAMPOS, D.A.; SOUZA, C.R.G; FERNANDES, A.C.S. (Edit.) Sítios geológicos e paleontológicos do Brasil. Brasília: CPRM, 2009. P.203-212.

SALGADO, A.A.R.; MAGALHÃES JUNIOR, A.P. Impactos da silvicultura de eucalipto no aumento das taxas de turbidez das águas fluviais: o caso de mananciais de abastecimento público de Caeté/MG. Geografias, Belo Horizonte, v.2, n.1, p.47-57, 2006.

SARDINHA, D.S.; CONCEIÇÃO, F.T.; CARVALHO, D.F.; CUNHA, R.; SOUZA, A.D.G. Impactos do uso público em atrativos turísticos naturais no município de Altinópolis (SP). Revista de Geociências, São Paulo, v.26, n.2, p. 161-172, 2007.

SLAIBI, T.H.A. Área de Proteção Ambiental da Serra da Piedade: um estudo sobre patrimônio histórico-ambiental e participação social em Visconde de Rio Branco-MG. Viçosa, 189 p., 2005. Dissertação (Mestrado) - Universidade Federal de Viçosa, Viçosa.

TAUK, S.M. Análise ambiental: uma visão multidisciplinar. São Paulo: UNESP, 1995. 206p. 